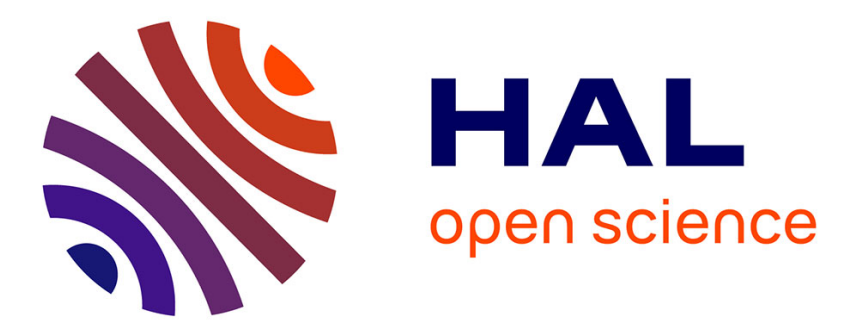

\title{
Age estimation from the biometric information of hand bones: Development of new formulas
}

Floriane Remy, Bérengère Saliba-Serre, Kathia Chaumoitre, Laurent

Martrille, Loïc Lalys

\section{To cite this version:}

Floriane Remy, Bérengère Saliba-Serre, Kathia Chaumoitre, Laurent Martrille, Loïc Lalys. Age estimation from the biometric information of hand bones: Development of new formulas. Forensic Science International, 2021, 322, pp.110777. 10.1016/j.forsciint.2021.110777 . hal-03231906

\section{HAL Id: hal-03231906 https://hal.science/hal-03231906}

Submitted on 22 Nov 2021

HAL is a multi-disciplinary open access archive for the deposit and dissemination of scientific research documents, whether they are published or not. The documents may come from teaching and research institutions in France or abroad, or from public or private research centers.
L'archive ouverte pluridisciplinaire HAL, est destinée au dépôt et à la diffusion de documents scientifiques de niveau recherche, publiés ou non, émanant des établissements d'enseignement et de recherche français ou étrangers, des laboratoires publics ou privés.

\section{(ㅇ)(1) $\$$}

Distributed under a Creative Commons Attribution - NonCommercial - NoDerivatives $\mid 4.0$ 


\begin{abstract}
INTRODUCTION: In the judicial context of the age estimation of living individuals, a new method was recently proposed, based on the collection of biometric information on hand bones radiographs. The aim of this study was to apply this method to a large French sample to provide new tools for age estimation. MATERIALS AND METHODS: The study sample consisted of metacarpals and proximal phalanges measurements of 1003 individuals aged less than 21 years. This sample was divided into two subgroups 1-12 and 13-21 years as the age of 13 is a relevant legal threshold for most European countries. A quadratic discriminant analysis was performed to identify the group to which an individual was most likely to belong. Age estimation formulas were also constructed from linear models: for each subgroup and the total sample. RESULTS: The belonging of an individual to the 1-12 or 13-21 subgroup was determined with a correct classification rate of $89.8 \%$. Age estimation formulas became less precise with age, with a mean absolute error ranging between 11 and 21 months. CONCLUSION: We proposed a two-step procedure for age estimation: firstly, the identification of the age group to which the individual is most likely to belong, and secondly, the age estimation of this individual by applying the appropriate formula.
\end{abstract}

KEYWORDS: Age estimation; Age prediction; Biometry; Hand bones; Skeletal age 


\section{INTRODUCTION}

Due to increasing transnational migratory activity, many individuals do not possess the necessary documentation to provide conclusive evidence of their age [1]. Yet, in most European countries, individuals under the age of 13, 18 and 21 have special rights and access to special protection [2]. In criminal proceedings, the legal authority often asks for expert analysis to determine whether an individual has reached the age they claim to be, so that they can rightfully receive special legal treatment based on their actual age [3]. Regarding age estimation in living individuals, the International Interdisciplinary Study Group of Forensic Age Diagnostics [4,5] recommends estimating the skeletal age, in addition to a physical inspection [6] and dental examination [7].

Experts have numerous methods for estimating a person's age [5]. Because hand ossification is considered to be representative of skeletal maturation as a whole, age can be estimated using hand-based methods [8]. The best-known method uses the Greulich \& Pyle's Atlas (GPA) [9]. It is a qualitative method, based solely on the observation of x-rays, implying varying results among and between observers [10-12]. This atlas is based on the study of hand radiographs of early $20^{\text {th }}$ century North Americans. Moreover, it has been demonstrated that this method can incorrectly estimate age in foreign populations [13], such as French individuals [14]. Another method currently used for estimating skeletal age is that developed by Tanner \& Whitehouse (TW) [15-17]. However, its results for age estimation do not appear to be better than those obtained by the GPA method [18].

Since the relevance of the GPA and TW methods is debatable, current research in the field of age estimation aims to develop new methods based on a quantitative approach. We [19] recently proposed to estimate age through a biometric analysis of hand bones: in this previous study, age was estimated based on measurements of metacarpals and proximal phalanges. Four age-group-specific formulas were developed, defined by the relevant legal age thresholds applicable in France (0-13, 13-18, 18-21 and 0-21 years). However, these formulas suffer from practical limitations as they may only be used following a decision regarding the minority of majority of an individual.

Therefore, the aim of the present study was to apply the biometric method previously developed to establish new formulas for the more global age groups: 1-21, 1-12 and 13-21 years. The decision to apply one of these formulas would be determined according to the results of the discriminant analysis.

\section{MATERIALS AND METHODS}

\section{a. Materials}

The study sample was composed of one thousand and three (1003) frontal hand radiographs of healthy individuals aged less than 21 years. These medical images were performed for medical reasons unrelated to the present research, at Nancy and Marseille University Hospital (France), between 2014 and 2018. They were retrospectively collected in the Picture Archiving and Communication System (PACS) of these medical institutions while preserving the patients' anonymity. The level of irradiation associated to hand radiographs was very low 
as the dosimetry of a hand x-rays is in the range of $0.2 \mu \mathrm{Sv}$, which corresponds to approximately 1 hour of natural irradiation.

The age of 13 being a relevant legal threshold for most European countries, the total study sample was divided into two subgroups: 1-12, and 13-21 years. Indeed, in some judicial system, as in France, detention or custodial sentences are impossible below the age of 10 years old and there may be an increased punishment for adults exploiting a child under 6 years old to beg on public road. This division at the age of 13 years old was also justified by the evolution of the correlation between age and the hand bones biometric measurements observed in a precedent paper: this relation became less linear from the ages of 13-15 years as the inter-individual variability became more important [19]. This observation may be explained by the non-synchronous maturation observed from this age period [20,21].

Respectively, these subgroups included five hundred and ninety-five (595) individuals aged between 1 and 12.98 years old, and four hundred and eight (408) individuals aged between 13.02 and 20.99 years old. The radiographs were balanced for sex and age class: for each age class, a minimum of 20 boys and 20 girls were included. An age class $k$ was defined as a class including individuals whose age lies in the range $k \leq$ age $<k+1$ years old.

For each individual, measurements were collected following the protocol previously developed [19] with the ORS $^{\circledR}$ (Object Research System) Visual ${ }^{\circledR}$ software specializing in medical image processing, and the "HandBones" plug-in, also developed in the same previous publication [19]. Thus, the length (LG), the proximal width (PW) and the distal width (DW) were obtained for each metacarpal and proximal phalange (named, respectively, $\mathrm{MC} i$ and $\mathrm{PH} i$, where $i$ refers to the corresponding ray number) of the five hand rays: see Fig.

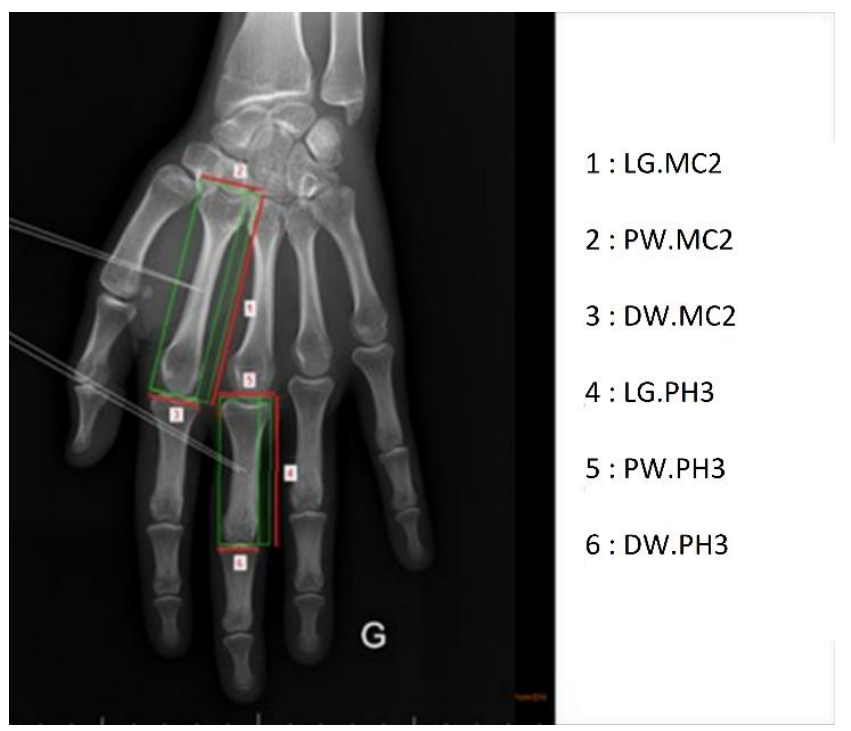

1. 
Fig. 1 Representation of six measurements collected for each metacarpal and proximal phalange of the five hand rays (from top to bottom: the length, proximal width and distal width of the second metacarpal and of the third proximal phalange) - from Remy et al. [19]

\section{b. Statistical analyses}

The study sample was divided into two subsamples using the surveyselect procedure of the SAS 9.4 software (SAS Institute Inc., Cary, NC, USA): one to build the discriminant function and age estimation formulas, and another for their evaluation (named respectively training and test samples). These subsamples were obtained with a stratified sampling method according to age and sex, with a sampling rate equal to $75 \%$. Thus, the proportions of individuals aged under 13 and those aged between 13 and 21 years old were respected. The training sample was composed of seven hundred and sixty-eight (768) individuals, whereas the test sample gathered two hundred and thirty-five (235) subjects. Statistical analysis was performed using RStudio $^{\circledR}$ (version 3.6.1 - (C) 219-218 RStudio, Inc.) [22]. The significance threshold was set to $5 \%$.

First, a discriminant analysis was carried out to determine the probability of an individual belonging to the 1-12 or 13-21 age group.

The Wilk's Lambda criterion was used to identify the most significant variables in the separation of these groups: the closer to 0, the stronger the discrimination. Any collinear variables among those previously selected $\left(R^{2}>0.90\right)$ were removed from the discriminant analysis.

According to the Kullback test results, the assumption of equal covariance matrices was not satisfied. Thus, a Quadratic Discriminant Analysis (QDA) was performed on the training sample to build the predictive model for age group membership: 1-12 or 13-21. Prior probabilities of group membership were set equal to class proportions for the training sample.

Then, age estimation formulas were established based on the linear stepwise regression method on training samples, for the age groups 1-12, 13-21 and 1-21 and respectively named $A g e_{1-12}, A_{g e_{13-21}}$ and $A g e_{1-21}$. The selection of the most relevant variables (i.e. biometric measurements) was based on the Bayesian Information Criterion (BIC). Here again, any collinear variables among those selected $\left(\mathrm{R}^{2}>0.90\right)$ were removed from the model.

The precision of these formulas was evaluated using residual analysis on the test sample, a residual being defined as the difference between the chronological and the estimated ages. Estimation was assumed to be precise when the absolute value of the residual was inferior to 12 months and acceptable when it ranged between 12 and 18 months. A negative residual value indicated an overestimation. Finally, the Mean Absolute Error (MAE) was also computed for each formula to assess their precision. The closer to 0 this value is, the closer to the chronological age is the estimation. 


\section{RESULTS}

The combination of two variables was retained as being the most discriminating for the distinction of the 1-12 and 13-21 age groups: the distal width of the fifth proximal phalange (DW_PH5) and the proximal width of the fourth metacarpal (PW_MC4). The corresponding Wilk's Lambda was equal to 0.29 .

From the Quadratic Discriminant Analysis, the following equations can be applied to determine the probability of an individual belonging to the 1-12 or 13-21 age group (respectively $p_{1-12}$ and $p_{13-21}$ ):

$$
\begin{aligned}
& p_{1-13}= \\
& \frac{e^{\left[-\frac{1}{2}\left(29.91+2.67 X_{1}-13.01 X_{2}-3.29 X_{1} X_{2}+1.02 X_{1}{ }^{2}+3.34 X_{2}{ }^{2}\right)+1.43\right]}}{e^{\left[-\frac{1}{2}\left(29.91+2.67 X_{1}-13.01 X_{2}-3.29 X_{1} X_{2}+1.02 X_{1}{ }^{2}+3.34 X_{2}{ }^{2}\right)+1.43\right]}+e^{\left[-\frac{1}{2}\left(134.27-6.82 X_{1}-18.72 X_{2}-1.47 X_{1} X_{2}+0.78 X_{1}{ }^{2}+2.01 X_{2}{ }^{2}\right)+1.76\right]}} \\
& p_{13-21}= \\
& \frac{e^{\left[-\frac{1}{2}\left(134.27-6.82 X_{1}-18.72 X_{2}-1.47 X_{1} X_{2}+0.78 X_{1}{ }^{2}+2.01 X_{2}{ }^{2}\right)+1.76\right]}}{e^{\left[-\frac{1}{2}\left(29.91+2.67 X_{1}-13.01 X_{2}-3.29 X_{1} X_{2}+1.02 X_{1}{ }^{2}+3.34 X_{2}{ }^{2}\right)+1.43\right]}+e^{\left[-\frac{1}{2}\left(134.27-6.82 X_{1}-18.72 X_{2}-1.47 X_{1} X_{2}+0.78 X_{1}{ }^{2}+2.01 X_{2}{ }^{2}\right)+1.76\right]}}
\end{aligned}
$$

where $X_{1}$ is the value of the proximal width of the fourth metacarpal (PW_MC4) and $X_{2}$ is the distal width of the fifth proximal phalange (DW_PH5) and $e$ denotes the exponential function.

For instance, an individual whose DW_PH5 and PW_MC4 measurements were equal to 10.73 $\mathrm{mm}$ and $15.06 \mathrm{~mm}$ respectively, according to the $p_{13-21}$ formula, has a probability of 0.994 of belonging to the 13-21 age group and a probability of 0.006 of belonging to the 1-12 age group.

When applied on the test sample, this model predicted the belonging to each age group with an $89.8 \%$ overall rate of correct classification. The rate of correct classification for the 1-12 and $13-21$ was $89.3 \%$ and $90.5 \%$ respectively.

Once the probability of an individual belonging to one age group or another has been determined, the most appropriate age estimation formula can be applied. When the posterior probability cannot be considered as discriminating enough, the global formula for the 1-21 age group can be applied.

From the different linear stepwise regressions, three, three and two variables were respectively selected for the establishment of the 1-12, 13-21 and 1-21 age estimation formulas, summarized below:

$$
\begin{aligned}
& -A^{-} e_{1-12}=0.353 * L G . M C 1-0.337 * D W . P H 5+0.392 * P W . M C 4-5.491 \\
& -A e_{13-21}=0.555 * D W . M C 2+0.685 * D W . P H 5-0.284 * P W . M C 2+6.979 \\
& -\quad \text { Age }_{1-21}=0.853 * D W . M C 4+1.231 * P W . P H 5-12.063
\end{aligned}
$$


The evaluation of these formulas' precision when applied to the test sample is summarized in Table 1 and Fig. 2.

Table 1 Evaluation of the three age estimation formulas on the test samples

\begin{tabular}{|l|c|c|c|}
\hline & $\begin{array}{c}\mathbf{1 - 1 2} \\
(\mathbf{n = 1 3 9}) * * *\end{array}$ & $\begin{array}{c}\mathbf{1 3 - 2 1} \\
(\mathbf{n = 9 5})\end{array}$ & $\begin{array}{c}\mathbf{1 - 2 1} \\
(\mathbf{n = 2 3 5})\end{array}$ \\
\hline MAE (in months) & 10.53 & 21 & 19.2 \\
\hline $\begin{array}{l}\text { Overestimation } \\
\text { (residual*<0) }\end{array}$ & $\begin{array}{c}58.3 \% \\
(\mathrm{n}=81)\end{array}$ & $\begin{array}{c}50.5 \% \\
(\mathrm{n}=48)\end{array}$ & $\begin{array}{c}53.6 \% \\
(\mathrm{n}=126)\end{array}$ \\
\hline $\mid$ residual|**<12 months & $\begin{array}{c}61.9 \% \\
(\mathrm{n}=86)\end{array}$ & $\begin{array}{c}35.8 \% \\
(\mathrm{n}=34)\end{array}$ & $\begin{array}{c}44.2 \% \\
(\mathrm{n}=104)\end{array}$ \\
\hline $\mid$ residual|**<18 months & $\begin{array}{c}80.6 \% \\
(\mathrm{n}=112)\end{array}$ & $\begin{array}{c}41.0 \% \\
(\mathrm{n}=39)\end{array}$ & $\begin{array}{c}56.6 \% \\
(\mathrm{n}=133)\end{array}$ \\
\hline
\end{tabular}

$*$ residual $=$ chronological age - estimated age

** $\mid$ residual $\mid=$ absolute value of the difference chronological age - estimated age

*** One individual was excluded from the initial 1-12 test sample as the value of its PW.MC4

was inferior to the minimal value of the 1-12 training sample range 


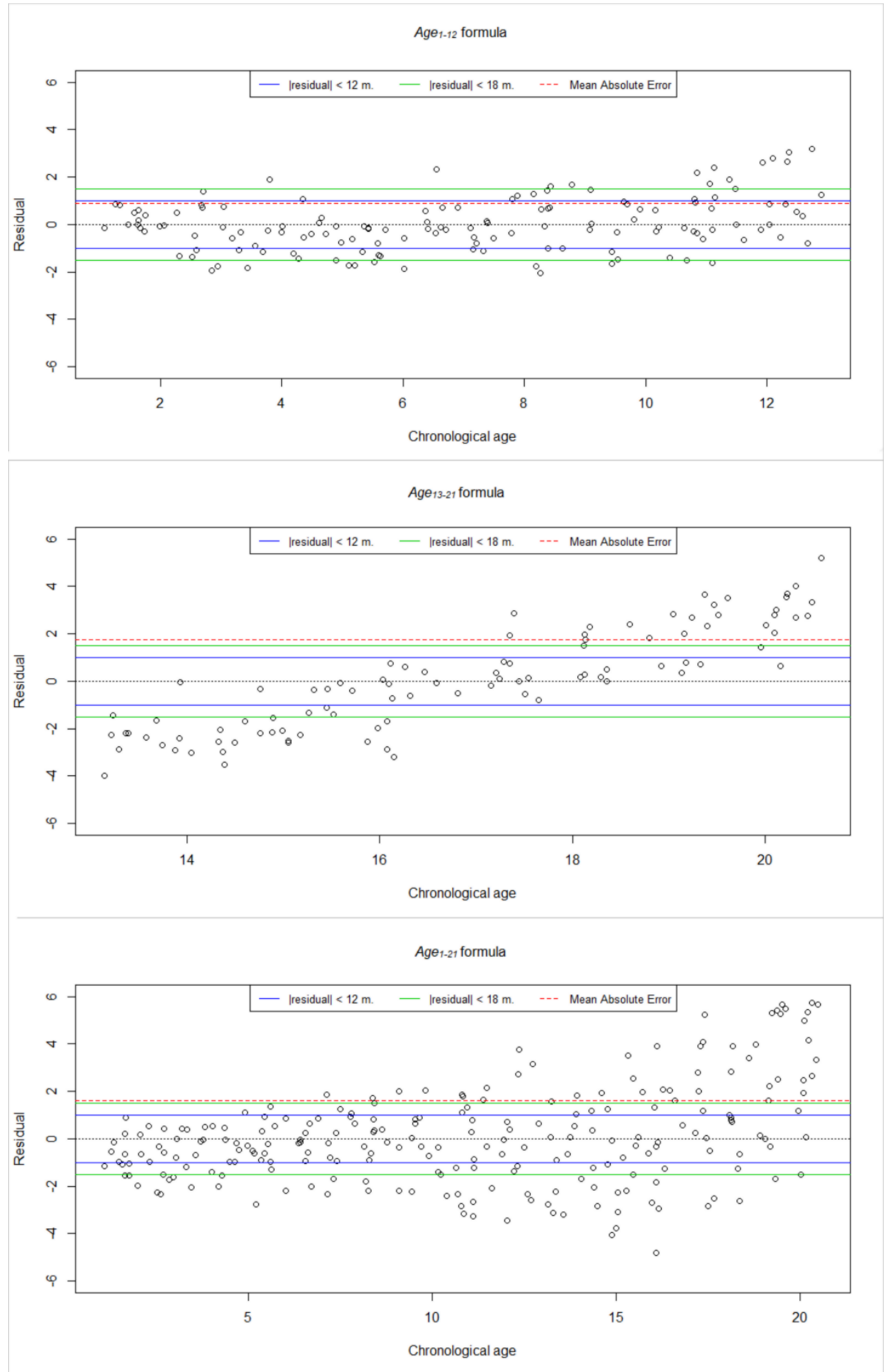

Fig. 2 Scatterplots illustrating the dispersion of residuals (i.e. error of estimation, in years) according to chronological age (in years) for the formulas $\mathrm{Age}_{1-12}$ (top), Age $_{13-21}$ (middle) and $A g e_{1-21}$ (bottom) when applied to the test samples. Previously defined thresholds were outlined: a blue and a green solid line represent the \pm 12 and \pm 18 months thresholds, respectively. The red dotted line represents the Mean Absolute Error. 


\section{DISCUSSION}

Due to the increase in transnational movements of people without any identification documents, proof of the age of migrants is a problematic issue in the judicial context. The most popular methods available for age estimation, the GPA [9] and the TW method [16,17], are not reliable enough: because they are based on a simple reading of the hand radiographs, the results are observer-dependent [10-12]. Yet, studies focusing on the evaluation of skeletal maturation through measurements are still rare [23-25]. Likewise, the development of software programs for estimating hand bones maturation is quite recent [26]. We previously proposed an estimation of age based on the biometric information of hand bones: four formulas were developed for the 0-21, 0-13, 13-18 and 18-21 years-old subgroups using measurements of the metacarpals and proximal phalanges [19].

However, this approach had a practical limitation. Indeed, in the judicial context, age estimation in mainly required when an individual's minority vs. majority is in question. Thus, the formulas previously developed for the 13-18 and 18-21 age groups were not appropriate as they could only be used after a decision had already been made regarding the potential minority or adulthood of the individual. To solve this issue, we proposed to develop a new formula for the 13-21 years-old subgroup. At the same time, we increased the sample size and applied cross-validation.

Moreover, the current study sample included both individuals from Nancy and Marseille (France), so it considers the south-north France variability. Thus, we may assume that the results presented in this paper would be the same if the method were applied on another European sample. This should be validated in future studies.

We proposed a two-step procedure where the probability of an individual belonging to the 112 or 13-21 age group was determined first, so that the most suitable age estimation formula could be then applied. These formulas may only be applied if the investigated individual's hand bones measurements range between the minimum and maximum values specified in the supplementary material.

Thus, we recommend first applying the discriminant functions proposed in this paper in order to identify the appropriate formula that will allow a more precise estimate of an individual's age. The quadratic discriminant analysis performed in this study concluded that an individual belongs to the 1-12 or 13-21 age group with an overall correct classification rate close to $90 \%$. The classification was equally as effective globally as within each age group.

Once the probability that an individual is under or over the age of 13 has been determined, the appropriate age estimation formula can be applied. But when the posterior probability, that is the probability of belonging to one age group or another, is close to 0.50 , the true membership of the observation may be questionable. Thus, the expert may choose a threshold or a 
minimum probability for classification ( 0.85 for example) so they can decide to continue or not by applying the appropriate age estimation formula $\left(A g e_{1-12}\right.$ or $\left.A g e_{13-21}\right)$. When no posterior probability is greater than the chosen threshold, we recommend applying the global age estimation formula $\mathrm{Age}_{1-21}$ instead of one specific formula to one age group or another.

Regarding the age estimation formulas, we noticed that their precision decreases as children get older, especially from the age of 13-15 years. Indeed, for the 13-21 age group, age was estimated at \pm 18 months for only $41 \%$ of the sample whereas age was estimated at \pm 12 months for almost 2/3 of the 1-12 subsample. Likewise, the general $\mathrm{Age}_{1-21}$ formula became less precise as children grew, especially from around 15 years of age. This loss in precision during this age period, which represents the end of hand bone maturation [27], has also been observed in other studies [19,28]. For instance, with the GPA, Chaumoitre et al. computed age prediction intervals at $95 \%$ of approximately 4 years after 10 years of age [29]. To improve these results, we may suggest developing sex-specific age estimation formulas. Indeed, previous studies have highlighted a sexual dimorphism in hand bone maturation from the ages of 10 and 12 years for girls and boys respectively [27,30]. Besides, the GPA and TW methods consider girls and boys separately $[9,16,17]$. However, such formulas would require knowing a priori the sex of the studied individual, which can be difficult when dealing with unidentifiable corpses.

For each formula, we also observed that age is overestimated for about $50 \%$ of the sample. This overestimation tendency is also observed by Pinchi et al. who applied the GPA and TW method to an Italian sample of individuals aged between 6 and 20 years: $40 \%$ to $73 \%$ of these subjects had an overestimated age compared to chronological age. Yet overestimating chronological age is problematic in the judicial context because individuals could be declared older than they actually are, when there should be a systematic presumption of minority $[11,31,32]$. We may hypothesize that this overestimation tendency is explained by the growth kinetics which are influenced by several factors both at an individual (ex. hormones, metabolism, age) and populational levels (ex. alimentation, ecology, environment) [33,34]. As the medical images analyzed in the present paper were retrospectively collected, we did not have access to such information. Future prospective studies should be considered to answer this question. This inclusion of additional information may improve the precision of the age estimation formulas. Nevertheless, this kind of information is not available in the judicial context of migrants' age estimation or when dealing with unidentifiable corpses.

These results may raise the question of the relevance of developing age estimation formulas with linear models for these older age groups. Indeed, it seems that due to the great interindividual variability observed from the puberty period onwards, an accurate and precise age estimate remains difficult to achieve: whatever the method used, the age estimation result is always associated with a certain margin of error, especially for older individuals [14,19]. Moreover, in practical implementations, magistrates, or even clinicians, do not necessarily want to know what the individual's real age is, but rather what the likelihood is that this individual has reached a specific legal age threshold [7]. 
Although the estimated age got from the proposed formulas present some weakness in terms of accuracy and precision, the biometric method presented in this paper remains promising regarding its reliability. Indeed, the intra- and interobservers errors were previously evaluated on 30 individuals randomly selected from the Nancy population of the present total sample and were demonstrated to be excellent as we obtained an Intraclass Correlation Coefficient (ICC) quite close to 1 (with the reproducibility evaluated by three independent observers of three different level of expertise) [19]. Anyway, we should consider assessing this reliability of the method on the complete sample (Nancy and Marseille populations).

To answer this issue regarding the accuracy and precision of age estimate, the discriminant analysis approach giving the probability that an individual belongs to a given age group may be more of interest in this judicial context. In further studies, we might consider including more relevant minor thresholds. For instance, in most countries, minors' rights can only be applied from the age of 18 [3]. Likewise, unaccompanied foreigners under the age of 21 cannot be escorted back to the border and can benefit from specific support [35].

Anyway, in order to make an age estimate of children and young adults, the International Interdisciplinary Study Group of Forensic Age Diagnostics (AGFAD) recommends estimating age using a multi-disciplinary approach: a physical inspection and a dental examination should be combined with the assessment of skeletal age [6,7,36,37]. We propose to integrate this two-step procedure for age estimation, with an automatization of the formulas to facilitate the practitioner's approach. To be validated, and even though we performed a cross-validation in this study, this method should be applied on a completely different sample.

\section{CONCLUSION}

In this study, we applied an objective and quantitative method for estimating age. We proposed a two-step procedure for age estimation based on the biometric information of hand bones collected on x-rays:

- First, the age group to which an individual is most likely to belong (1-12 or 13-21) should be determined by applying the discriminant functions developed in this paper;

- Then, according to the discriminant analysis results, the age of this individual can be estimated by applying the most appropriate formula $\left(A g e_{1-12}\right.$ or $\left.A g e_{13-21}\right)$. If the discriminant analysis results are not conclusive enough (probability close to 0.50 for example), the general $A g e_{1-21}$ formula can be applied instead.

\section{References}

[1] S. Angenendt, Asylum and migration policies in the European Union, Europa Union Verlag, Berlin, 1999. 


\section{[2] UNICEF,}

http://www.unicef.org/protection/files/Age_assessment_practice_literature_review_FR.p df, (n.d.).

[3] V. Hazebroucq, À la recherche de la meilleure méthode possible de détermination radiologique de l'âge osseux à des fins judiciaires : y aurait-il une bonne réponse à une mauvaise question ?: Determination of radiographic bone age for medico-legal purposes: looking for the best answer to this question, J. Radiol. 89 (2008) 1895-1896. https://doi.org/10.1016/S0221-0363(08)74783-8.

[4] Charité - Universitätsmedizin Berlin: Charité, (n.d.). http://www.charite.de/charite/ (accessed July 6, 2015).

[5] J.M. Tanner, Growth at adolescence. (2nd ed.), Springfield, Ill., Thomas, 1962.

[6] A. Olze, W. Reisinger, G. Geserick, A. Schmeling, Age estimation of unaccompanied minors: Part II. Dental aspects, Forensic Sci. Int. 159, Supplement (2006) S65-S67. https://doi.org/10.1016/j.forsciint.2006.02.018.

[7] A. Schmeling, C. Grundmann, A. Fuhrmann, H.J. Kaatsch, F. Ramsthaler, W. Reisinger, T. Riepert, S. Ritz-Timme, F.W. Rösing, K. Rötzcher, G. Geserick, Criteria for age estimation in living individuals, Int. J. Legal Med. 122 (2008) 457-460.

[8] F. Schmid, H. Moll, Atlas der Normalen und Pathologischen Handskeletentwicklung, Springer-Verlag, 2013.

[9] W.W. Greulich, S.I. Pyle, Radiographic Atlas of Skeletal Development of the Hand and Wrist, Stanford University Press, 1959.

[10] N. Lynnerup, E. Belard, K. Buch-Olsen, B. Sejrsen, K. Damgaard-Pedersen, Intra- and interobserver error of the Greulich-Pyle method as used on a Danish forensic sample, $\begin{array}{lllll}\text { Forensic Sci. Int. } & 179 & \text { (2008) 242.e1-242.e6. }\end{array}$ https://doi.org/10.1016/j.forsciint.2008.05.005.

[11] S. Schmidt, I. Nitz, S. Ribbecke, R. Schulz, H. Pfeiffer, A. Schmeling, Skeletal age determination of the hand: a comparison of methods, Int. J. Legal Med. 127 (2013) 691698.

[12] B. Büken, Ö.U. Erzengin, E. Büken, A.A. Şafak, B. Yazıcı, Z. Erkol, Comparison of the three age estimation methods: Which is more reliable for Turkish children?, Forensic Sci. Int. 183 (2009) 103.e1-103.e7. https://doi.org/10.1016/j.forsciint.2008.10.012.

[13] M. Mansourvar, M.A. Ismail, R.G. Raj, S.A. Kareem, S. Aik, R. Gunalan, C.D. Antony, The applicability of Greulich and Pyle atlas to assess skeletal age for four ethnic groups, J. Forensic Leg. Med. 22 (2014) 26-29. https://doi.org/10.1016/j.jflm.2013.11.011. 
[14] D. Zabet, C. Rérolle, J. Pucheux, N. Telmon, P. Saint-Martin, Can the Greulich and Pyle method be used on French contemporary individuals?, Int. J. Legal Med. 129 (2015) 171-177. https://doi.org/10.1007/s00414-014-1028-7.

[15] S. Schmidt, I. Nitz, R. Schulz, A. Schmeling, Applicability of the skeletal age determination method of Tanner and Whitehouse for forensic age diagnostics, Int. J. Legal Med. 122 (2008) 309-314.

[16] J.M. Tanner, Assessment of skeletal maturity and prediction of adult height (TW2 method), Academic Press, 1983.

[17] J. Tanner, M. Healy, H. Goldstein, N. Cameron, Assessment of Skeletal Maturity and Prediction of Adult Height (TW3 Method), W.B. Saunders, 2001.

[18] V. Pinchi, F. De Luca, F. Ricciardi, M. Focardi, V. Piredda, E. Mazzeo, G.-A. Norelli, Skeletal age estimation for forensic purposes: A comparison of GP, TW2 and TW3 methods on an Italian sample, Forensic Sci. Int. 238 (2014) 83-90. https://doi.org/10.1016/j.forsciint.2014.02.030.

[19] F. Remy, G. Hossu, R. Cendre, E. Micard, L. Mainard-Simard, J. Felblinger, L. Martrille, L. Lalys, Development of a biometric method to estimate age on hand radiographs, Forensic Sci. Int. $271 \quad$ (2017) 113-119. https://doi.org/10.1016/j.forsciint.2016.12.013.

[20] M. Deheeger, M.F. Rolland-Cachera, Étude longitudinale de la croissance d'enfants parisiens suivis de l'âge de 10 mois à 18 ans, Arch. Pédiatrie. 11 (2004) 1139-1144. https://doi.org/10.1016/j.arcped.2004.04.010.

[21] R. Hauspie, M. Vercauteren, C. Susanne, Secular changes in growth and maturation: an update, Acta Paediatr. 86 (1997) 20-27. https://doi.org/10.1111/j.16512227.1997.tb18364.x.

[22] R Core Team, R: A language and environment for statistical computing, R Foundation for Statistical Computing, Vienna, Austria, 2016.

[23] V. De Sanctis, S. Di Maio, A.T. Soliman, G. Raiola, R. Elalaily, G. Millimaggi, Hand Xray in pediatric endocrinology: Skeletal age assessment and beyond, Indian J. Endocrinol. Metab. 18 (2014) S63-71. https://doi.org/10.4103/2230-8210.145076.

[24] D. Frank, L. Rill, B. Kolarovszki, Á.K. Nagy, [Classical and modern methods for the assessment of skeletal maturation and pubertal growth spurt], Orv. Hetil. 159 (2018) 1423-1432. https://doi.org/10.1556/650.2018.31151.

[25] A. Manzoor Mughal, N. Hassan, A. Ahmed, Bone age assessment methods: a critical review, Pak. J. Med. Sci. 30 (2014) 211-215. https://doi.org/10.12669/pjms.301.4295. 
[26] H.H. Thodberg, L. Sävendahl, Validation and Reference Values of Automated Bone Age Determination for Four Ethnicities, Acad. Radiol. 17 (2010) 1425-1432. https://doi.org/10.1016/j.acra.2010.06.007.

[27] V. Abbassi, Growth and Normal Puberty, Pediatrics. 102 (1998) 507-511.

[28] M. Tisè, L. Mazzarini, G. Fabrizzi, L. Ferrante, R. Giorgetti, A. Tagliabracci, Applicability of Greulich and Pyle method for age assessment in forensic practice on an Italian sample, Int. J. Legal Med. 125 (2011) 411-416. https://doi.org/10.1007/s00414010-0541-6.

[29] K. Chaumoitre, B. Saliba-Serre, P. Adalian, M. Signoli, G. Leonetti, M. Panuel, Forensic use of the Greulich and Pyle atlas: prediction intervals and relevance, Eur. Radiol. 27 (2017) 1032-1043. https://doi.org/10.1007/s00330-016-4466-4.

[30] N. Kanbur-Oksüz, O. Derman, E. Kinik, Correlation of sex steroids with IGF-1 and IGFBP-3 during different pubertal stages, Turk. J. Pediatr. 46 (2004) 315-321.

[31] L. Hackman, S. Black, The reliability of the Greulich and Pyle atlas when applied to a modern Scottish population, J. Forensic Sci. 58 (2013) 114-119. https://doi.org/10.1111/j.1556-4029.2012.02294.x.

[32] S.T. Patil, M.P. Parchand, M.M. Meshram, N.Y. Kamdi, Applicability of Greulich and Pyle skeletal age standards to Indian children, Forensic Sci. Int. 216 (2012) 200.e1-4. https://doi.org/10.1016/j.forsciint.2011.09.022.

[33] A. Schmeling, W. Reisinger, D. Loreck, K. Vendura, W. Markus, G. Geserick, Effects of ethnicity on skeletal maturation: consequences for forensic age estimations, Int. J. Legal Med. 113 (2000) 253-258.

[34] A. Schmeling, R. Schulz, B. Danner, F.W. Rösing, The impact of economic progress and modernization in medicine on the ossification of hand and wrist, Int. J. Legal Med. 120 (2006) 121-126.

[35] J.-L. Rongé, L'expertise de détermination de l'âge : la vérité tombe toujours sur un os, J. Droit Jeunes. 285 (2009) 33-44. https://doi.org/10.3917/jdj.285.0033.

[36] A. Kumagai, G. Willems, A. Franco, P. Thevissen, Age estimation combining radiographic information of two dental and four skeletal predictors in children and subadults, Int. J. Legal Med. 132 (2018) 1769-1777. https://doi.org/10.1007/s00414018-1910-9.

[37] M. Macha, B. Lamba, J.S.S. Avula, S. Muthineni, P.G.J.S. Margana, P. Chitoori, Estimation of Correlation between Chronological Age, Skeletal Age and Dental Age in Children- A Cross-sectional Study, J. Clin. Diagn. Res. JCDR. 11 (2017) ZC01-ZC04. https://doi.org/10.7860/JCDR/2017/25175.10537. 


\section{Funding}

This research did not receive any specific grant from funding agencies in the public, commercial, or not-for-profit sectors. 